\title{
Characterization and application of a new natural catalyst
}

\author{
Francisco Delgado $^{a^{*}}$, Hulme Ríos ${ }^{b}$, Juan-Manuel Aceves ${ }^{b}$, Guillermo Penieres ${ }^{b}$, \\ Gabriel Arroyo ${ }^{b}$, Benjamin Velasco ${ }^{b}$, and René Miranda ${ }^{b}$ \\ ${ }^{a}$ Escuela Nacional de Ciencias Biológicas, Instituto Politécnico Nacional, Prolongación Carpio \\ y Plan de Ayala, Casco de Santo Tomás, México, D. F. 11340, México \\ ${ }^{b}$ Facultad de Estudios Superiores Cuautitlán, Campo 1, Universidad Nacional Autónoma de \\ México Cuautitlán Izcalli, Estado de México 54740, México \\ E-mail fdelgado@woodward.encb.ipn.mx
}

(received 10 Sep 03; accepted 24 Nov 03; published on the web 28 Nov 03)

\begin{abstract}
This paper is focused on the characterization and study of the catalytic properties of a natural soil from Etlá, Oaxaca, México. Thus, X-ray diffraction, energy dispersive spectroscopy, scanning electron microscopy, thermal methods, infrared spectroscopy, ${ }^{27} \mathrm{Al}$ and ${ }^{29} \mathrm{Si}$ solid-state NMR spectroscopy and surface adsorption properties $\left(\mathrm{N}_{2}-\mathrm{BET}\right)$ analyses for the target material were carried out. Additionally, in order to test the potential and effectiveness of this material as Lewis acid catalyst, a set of experiments for the promotion of various 1,3-oxathiolanes as well as ortho and para benzyltoluenes were carried out. It was found that the catalytic activity for these reactions depends on the amount of soil, the reaction time and the pyridine concentration used as competitive inhibitor. Finally, the studies on the characterization and uses of the soil were thought in order to contribute to the aim of the green chemistry, by using and promoting friendly environment natural materials.
\end{abstract}

Keywords: Bentonitic-zeolitic-soil, heterogeneous catalysis, benzyltoluenes, oxathiolanes

\section{Introduction}

The remarkable ability of some natural aluminosilic soils, such as zeolites and clays, to catalyze various chemical reactions and to undergo important structural changes controllably, has found widespread applications in the research and industry areas. Mainly, these materials have acquired important interest as catalysts, due to their usefulness, exceptionally high activity and environmental integrity, ${ }^{1}$ in a number of important model reactions. These include the DielsAlder reaction and Friedel-Crafts procedures, in addition to the synthesis of organosulfur synthons and electrochemical reactions, among others, and all with high selectivity. ${ }^{2}$ Moreover, with these kinds of materials, many reactions have been performed with activities and yields in 
excess of other well-known acid catalysts and consequently they are of current interest. ${ }^{3}$ So, it is not surprising that many research groups are now working in this area, in order to seek novel alternatives. However, there exist many natural aluminosilicates with interesting properties that remain to be discovered and utilized in terms of their catalytic characteristics, in spite of being known for other applications. In this sense, ZBSEO a Zeolitic Bentonitic Soil widely distributed at Etla in the state of Oaxaca in southern Mexico has been used for centuries as a construction material, due to its unique appearance. In addition to the scientific value of finding novel materials with unique properties, the employment of natural materials also has an important environmental side.

Also, it is worth mentioning that ZBSEO, has long been used for building amazing monuments and religious constructions of singular beauty around Oaxaca City; the beautiful Cathedral and the government buildings, in addition to the handcrafted pavement-tiles of the town city, which are made with this material, are outstanding examples. Thereby, the aim of the present work is to inform about the characterization and determination of the catalytic activity of the ZBSEO. Thus, it was analyzed by means of a set of analytical techniques: absorption (IRPy), X-ray diffraction (DRX), thermal analysis (DTG-G/DTA), nitrogen adsorption $\left(\mathrm{N}_{2}-\mathrm{BET}\right)$, energy dispersive spectroscopy (EDX), electronic microscopy (SEM), together with nuclear magnetic resonance in solid state (NMR-MAS). Then, ZBSEO was assayed as catalyst producing a set of eleven oxathiolanes in addition to the promotion of ortho and para benzyltoluenes. The first class of molecules were obtained from the corresponding carbonylic compounds in the presence of 2-mercaptoethanol, then toluene and benzylchloride were used in order to obtain the arylmethanes; both procedures by the catalytic action of the soil.

Complementarily, the reactions were optimized in terms of the amount of catalyst and the reaction time; additionally, the influence of pyridine as a competitive inhibitor was analyzed, demonstrating the Lewis acid character of the target catalyst. In this sense, the results show good yields, under mild conditions, and short reactions times, in addition to the ease of the experimental workup. Moreover, it is worth mentioning that according to the literature, the oxathiolanes have interesting biological and chemical applications such as: potent anti-HIV agents, ${ }^{4}$ anti-inflammatory, ${ }^{5}$ bactericidal, ${ }^{4-7}$ fungicidal, ${ }^{8}$ antimuscarinidal, ${ }^{9}$ herbicidal and fitocidal ${ }^{10}$ agents, as well being a masking group for carbonylic moieties. The benzyltoluenes are of industrial interest due to their application as insulting oils in high voltages electrical devices,

and as components of high-octane fuels for aircraft engines, among many others. ${ }^{11}$ Finally, it is important to note that the proposal of a natural aluminosilicate as novel catalyst represents an important and attractive alternative in the field of green chemistry, since it is part of the protocol of our research program. ${ }^{12}$

\section{Results and Discussion}




\section{Soil characterization}

The X-ray powder diffractogram of the soil (Figure 1) shows the presence of at least five phases, with $d$ values at $6.51,3.47,3.21,8.96,3.96,3.90,9.96,4.47,3.32,9.96,2.57,2.55,4.25,3.33$, $1.82 \AA$ corresponding to the diffraction pattern of mordenite $\left(\mathrm{Ca}, \mathrm{Na}_{2}, \mathrm{~K}_{2}\right) \mathrm{Al}_{2} \mathrm{Si}_{10} \mathrm{O}_{24} \cdot 7 \mathrm{H}_{2} \mathrm{O}$, clinoptilolite, $(\mathrm{K}, \mathrm{Na}, \mathrm{Ca})_{6}(\mathrm{Si}, \mathrm{Al})_{36} \mathrm{O}_{72} \cdot 20 \mathrm{H}_{2} \mathrm{O}$, illite, $\left(\mathrm{K}, \mathrm{H}_{3} \mathrm{O}\right) \mathrm{Al}_{2} \mathrm{Si}_{3} \mathrm{Al} \cdot 10(\mathrm{OH})_{2}$, muscovite $(\mathrm{K}$, $\mathrm{Na}) \mathrm{Al}_{2}(\mathrm{Si}, \mathrm{Al})_{4} \mathrm{O}_{10}(\mathrm{OH})_{2} ; \alpha$-quartz and cristobalite, respectively. Regarding with the surface properties of the material, the BET surface area was $45.09 \mathrm{~m}^{2} \mathrm{~g}^{-1}$, mean of three determinations; characteristic of low porosity material which is in accordance with BET constant $(\mathrm{C}=537.539)$ and the typical isotherm of the class II corresponding to the $\mathrm{N}_{2}$ adsorption obtained (Figure 2). In addition, the pore volume and pore average diameter were $0.102 \mathrm{~cm}^{3} \mathrm{~g}^{-1}$ and $98.243 \AA$ respectively. The scanning electronic microscopy show irregular shaped particles with variable sizes; this morphology was validated by the micrograph obtained at higher magnification, in this sense the soil is a very heterogeneous material (Figure 3). The supplementary energy dispersive $\mathrm{X}$-ray analysis provided the following elemental data: $\mathrm{SiO}_{2}(57.824 \%), \mathrm{Al}_{2} \mathrm{O}_{3}(9.730 \%), \mathrm{CO}_{2}$ (29.089\%), $\mathrm{K}_{2} \mathrm{O}(2.621 \%), \mathrm{CaO}(1.738 \%), \mathrm{Fe}_{2} \mathrm{O}(1.582 \%)$, with small quantities of $\mathrm{MgO}$ $(0.856 \%), \mathrm{Na}_{2} \mathrm{O}(0.274 \%)$. The two first oxide values were also determined through chemical analysis which showed good approximation $\left(\mathrm{SiO}_{2} 68.3 \%, \mathrm{Al}_{2} \mathrm{O}_{3} \quad 10.66 \%\right)$.

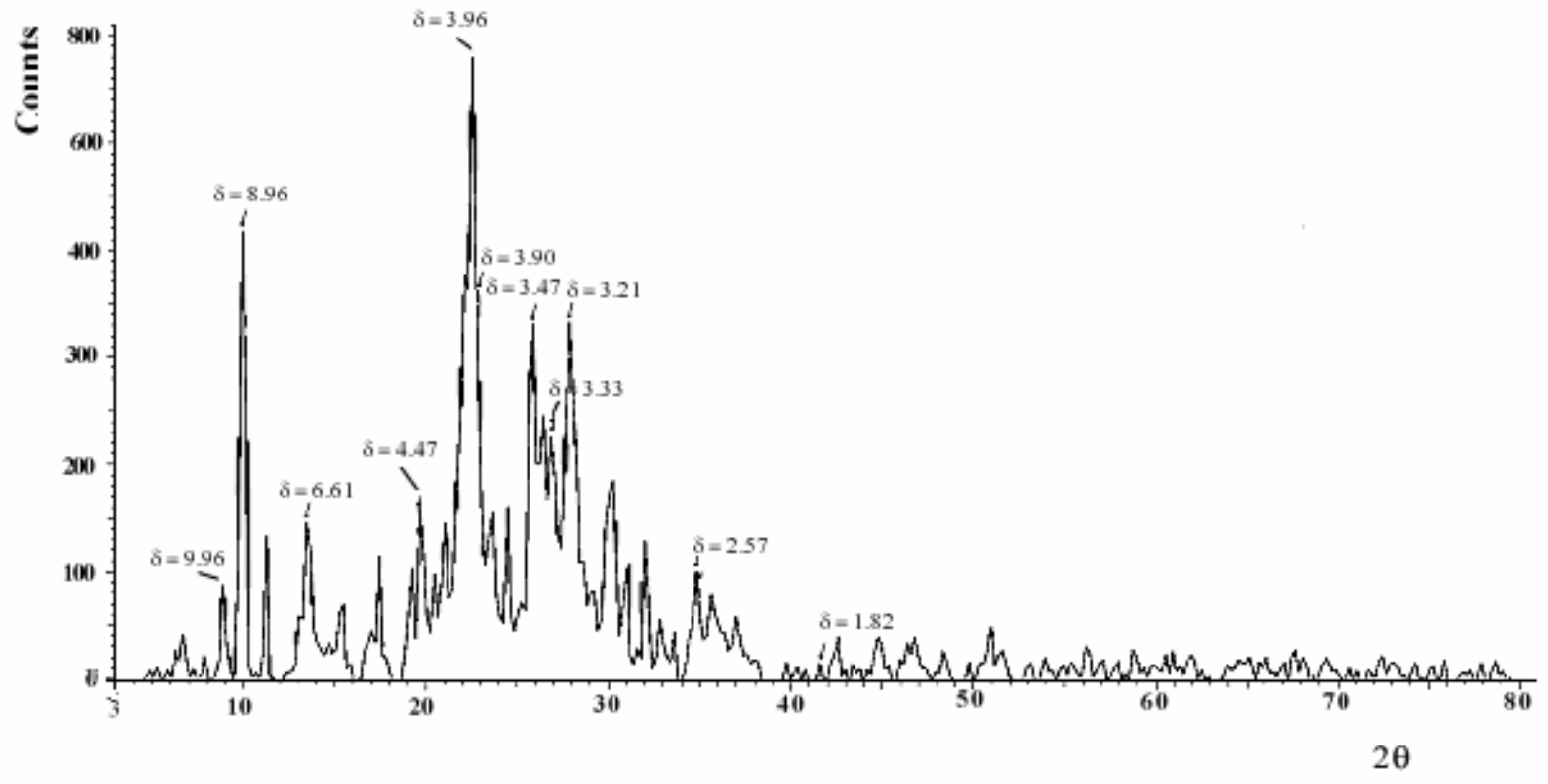

Figure 1. X-Ray diffraction patern of ZBSEO. 


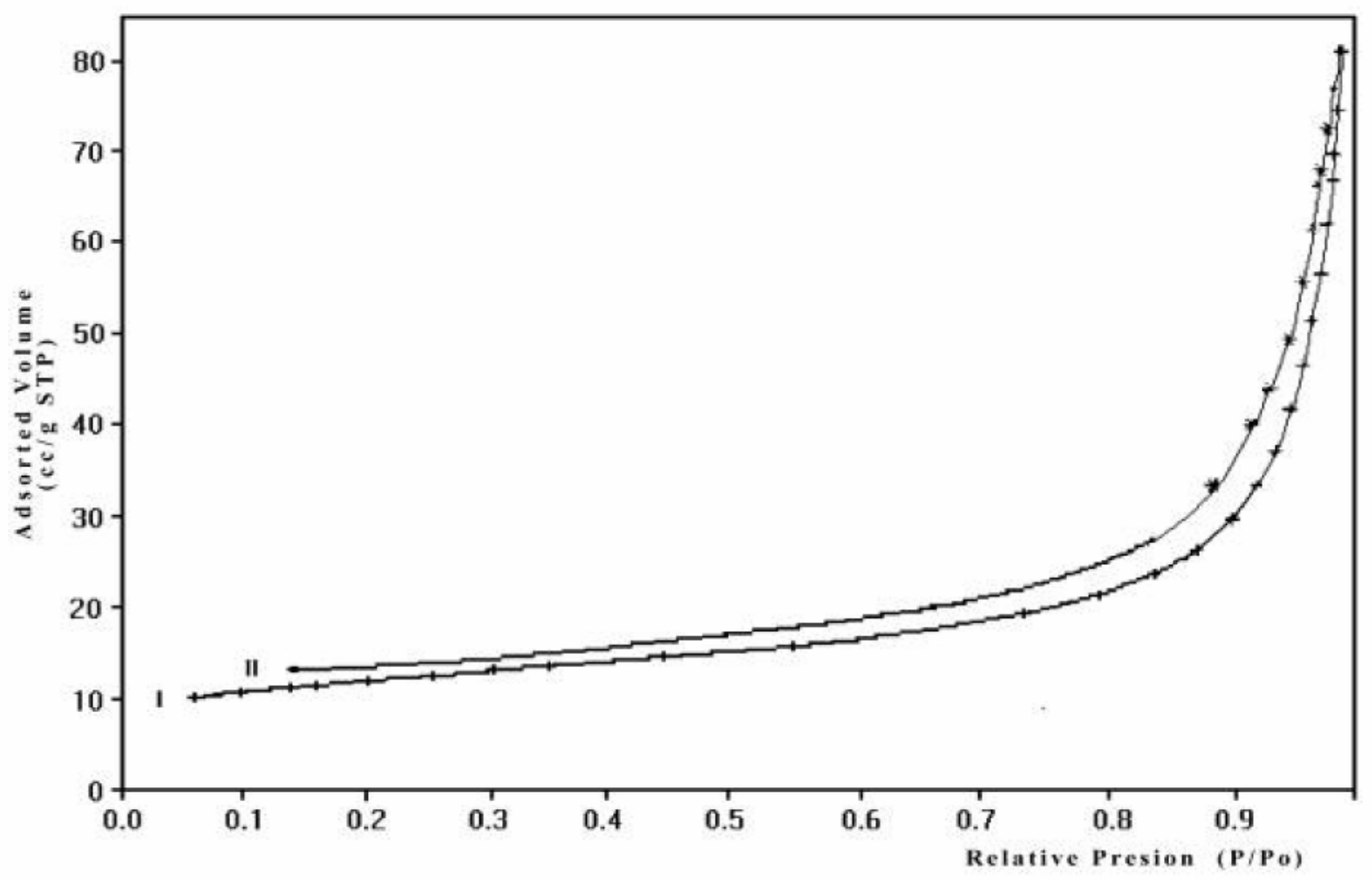

Figure 2. Absorption isotherms of $\mathrm{N}_{2}$ on ZBSEO.

The acidic nature of the catalyst was evaluated by infrared spectroscopy using pyridine as probe molecule. Two, infrared spectra are depicted in Figure 4, where there is exhibited a set of two bands at 1445 and $1541 \mathrm{~cm}^{-1}$; these absorption bands provide a strong indication of the presence of both Lewis and Brönsted-Lowry acid nature sites, respectively. It is worth mentioning that the absorption previously assigned to the coordinately bonded pyridine with Lewis sites, Lpy species, split into two new bands $\left(1448\right.$ and $\left.1438 \mathrm{~cm}^{-1}\right)$ at higher temperature. This phenomenon was explained by admitting the presence of two Lewis sites with different strength constant. According to T. Cseri and coworkers, ${ }^{13}$ the former band at $1448 \mathrm{~cm}^{-1}$ corresponds to the coordination bond vibration of $\mathrm{Py}_{\gg} \mathrm{Al}^{+3}$ species, whereas the absorption band at $1438 \mathrm{~cm}^{-1}$ was considered to be due to the coordination bond of the Py with $\mathrm{Na}^{+}$ions. 

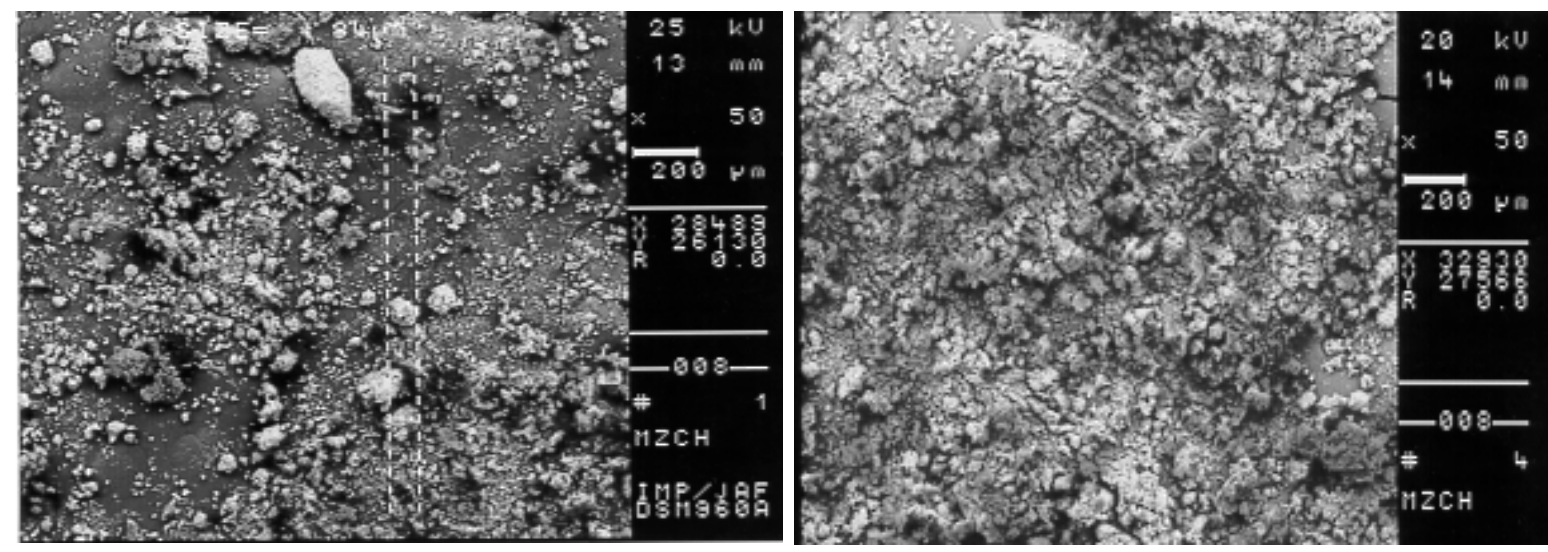

a (x 50)
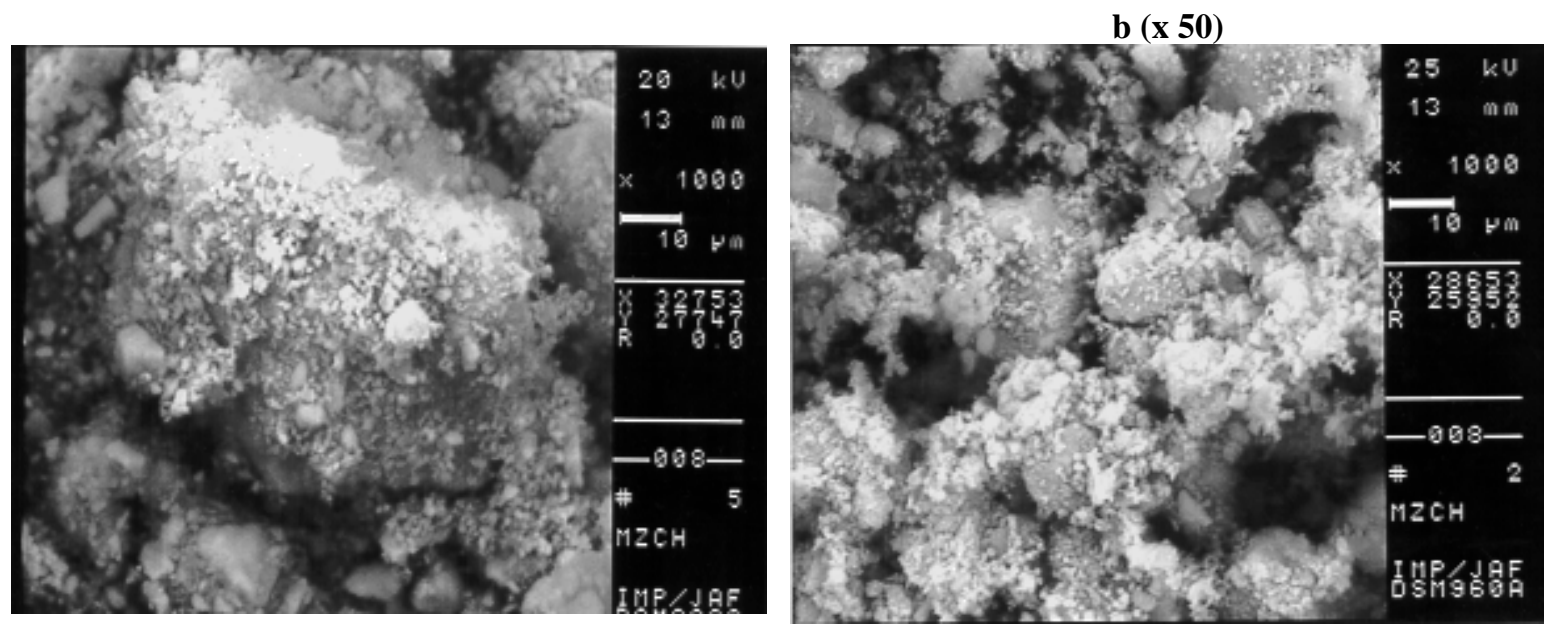

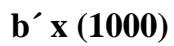

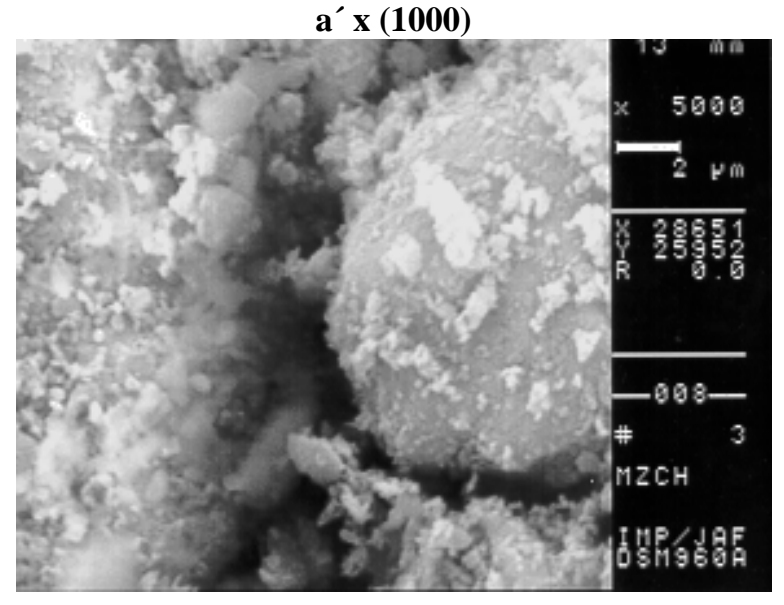

$a^{\prime \prime} \times(5000)$

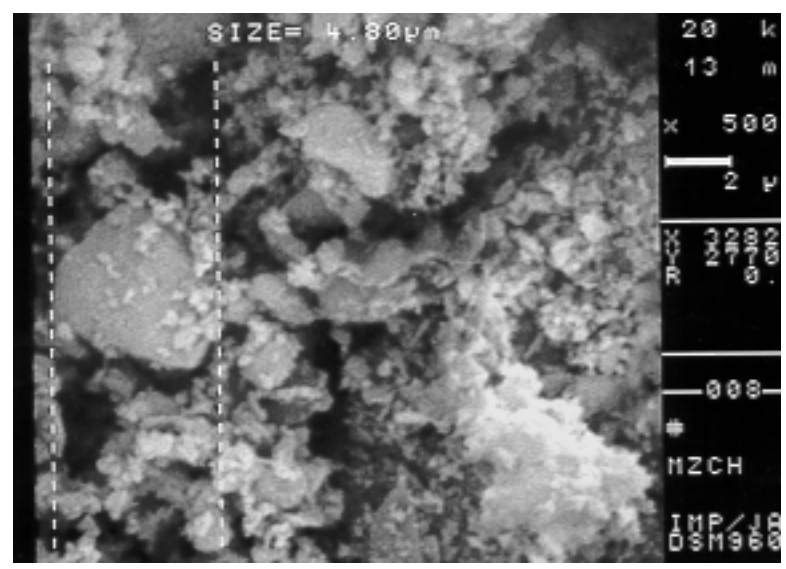

$b^{\prime \prime} \times(5000)$

Figure 3. Scanning electron micrographs of ZBSEO recorded at x50, x1000 and x5000 magnifications. 


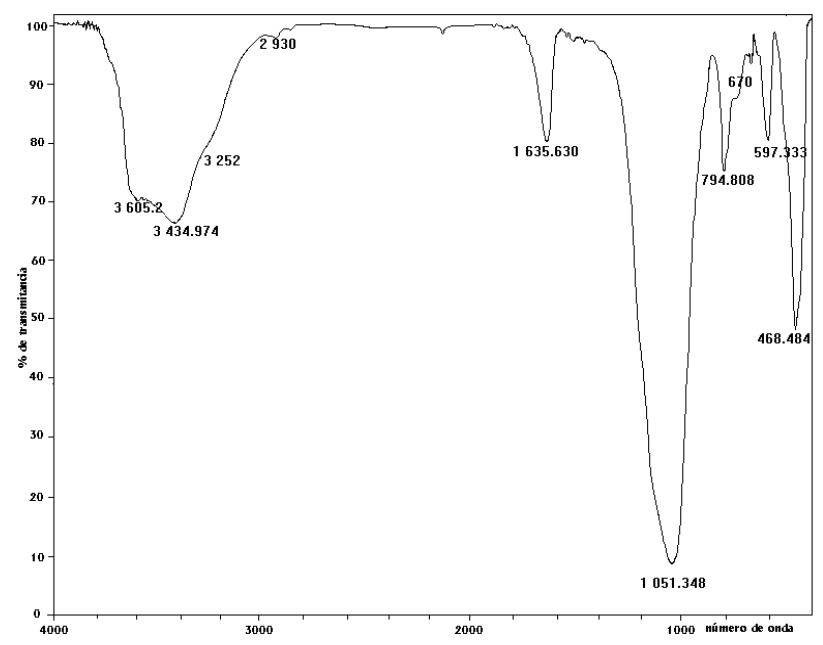

a

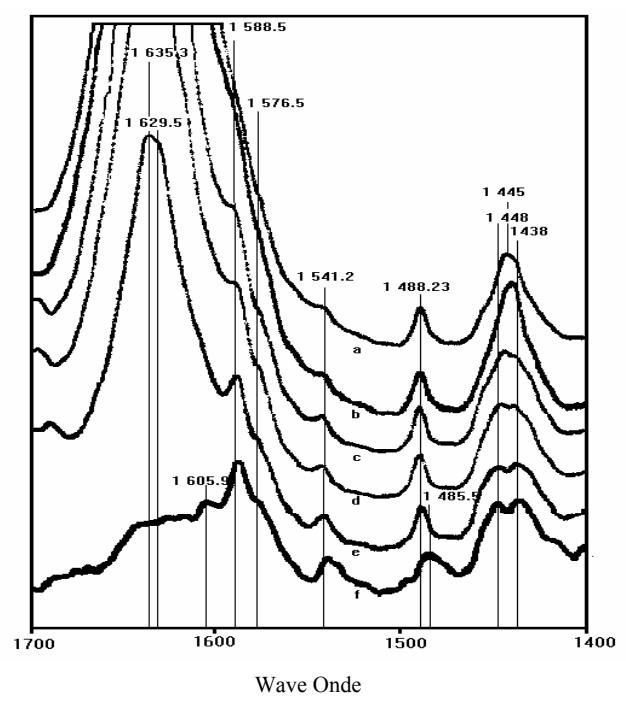

b

Figure 4. Infrared spectra of ZBSEO: (a) aluminosilicate and silicate typical framework absorption bands, (b) pyridine adsorbed on ZBSEO; spectra recorded under different temperature. Observe the gently split up of Lewis absorption as the temperature raised.

The concentrations of pyridine adsorbed, which were associated to Brönsted-Löwry, BPy, and Lewis, Lpy, acid centres in the ZBSEO material under increasing temperature, were calculated by means of the $1541 \mathrm{~cm}^{-1}$ band intensity for Bpy and the $1445 \mathrm{~cm}^{-1}$ band intensity for Lpy. ${ }^{14}$ In this regard, it is interesting to mention that, although the maximum concentration of Lpy, $314 \mu \mathrm{m} / \mathrm{g}$ was reached at $100{ }^{\circ} \mathrm{C}$, an important concentration of Lpy species exist at $50{ }^{\circ} \mathrm{C}$ (Table 1). In contrast, the Bpy concentration was not observed at the same temperature. Upon further heating, however, the Lewis acidic concentration decreased substantially, meanwhile the Brönsted-Löwry acidic nature increased progressively, from 0.0 to $37 \mu \mathrm{m} / \mathrm{g}$. This tendency was associated to the plausible proton transfer from the surface to the adsorbed molecule on the Lewis acid centre.

Table 1. Adsorption intensity and concentration of Brönsted-Löwry and Lewis acid centres under different thermal conditions*

\begin{tabular}{ccccccc}
\hline $\mathrm{T}^{\circ} \mathrm{C}$ & A.I.B. & $1490 \mathrm{~cm}^{-1}$ & A.I.L. & $\mu \mathrm{m} / \mathrm{g}(\mathrm{B})$ & $\mu \mathrm{m} / \mathrm{g}(\mathrm{L})$ & Acidity \\
\hline 50 & 0.00 & 1.07 & 5.63 & 0.00 & 218.00 & 218.00 \\
100 & 0.00 & 1.17 & 8.10 & 0.00 & 314.00 & 314.00 \\
200 & 0.17 & 1.03 & 5.96 & 7.00 & 231.00 & 238.00 \\
300 & 0.26 & 1.06 & 5.67 & 11.00 & 220.00 & 231.00 \\
400 & 0.55 & 1.02 & 4.61 & 23.00 & 179.00 & 202.00 \\
500 & 0.88 & 0.77 & 4.19 & 37.00 & 162.00 & 199.00 \\
\hline
\end{tabular}


*AIB and AIL denote the absorption of Brönsted and Lewis band. Bpy and Lpy indicate the concentration value of Brönsted and Lewis site.

The signals of ${ }^{29} \mathrm{Si}$ magic-angle spinning NMR spectrum recorded from ZBSEO material were overlapped to a great extent (Figure 5). This provided important information about the possible presence of different structural units. A deconvolution technique showed at least four well resolved resonance lines that were distinguished at $-93.61,-100.36,-106.52$ and -112.42 ppm with an intensity ratio of $8.75,29.19,51.33$ and $10.7 \%$. These signals were respectively attributed to four different types of ${ }^{29} \mathrm{Si}$ nuclear environments that were assigned to $\mathrm{Si}$ (3Al), $\mathrm{Si}$ (2Al), Si (1 Al) and $\mathrm{Si}(0 \mathrm{Al})$. It is worthy to point out that, by comparison to the values in the literature, there are high probabilities that these chemical shifts might corresponds to structural units of material as illite (-91 ppm), ${ }^{15}$ clinoptilolite $(-100.5,-106.9$ and $-112.8 \mathrm{ppm}),{ }^{16}$ mordenite $(-100,-106 \text { and }-113 \mathrm{ppm})^{17}$ as well as quartz $(-107.4 \mathrm{ppm}){ }^{18}$

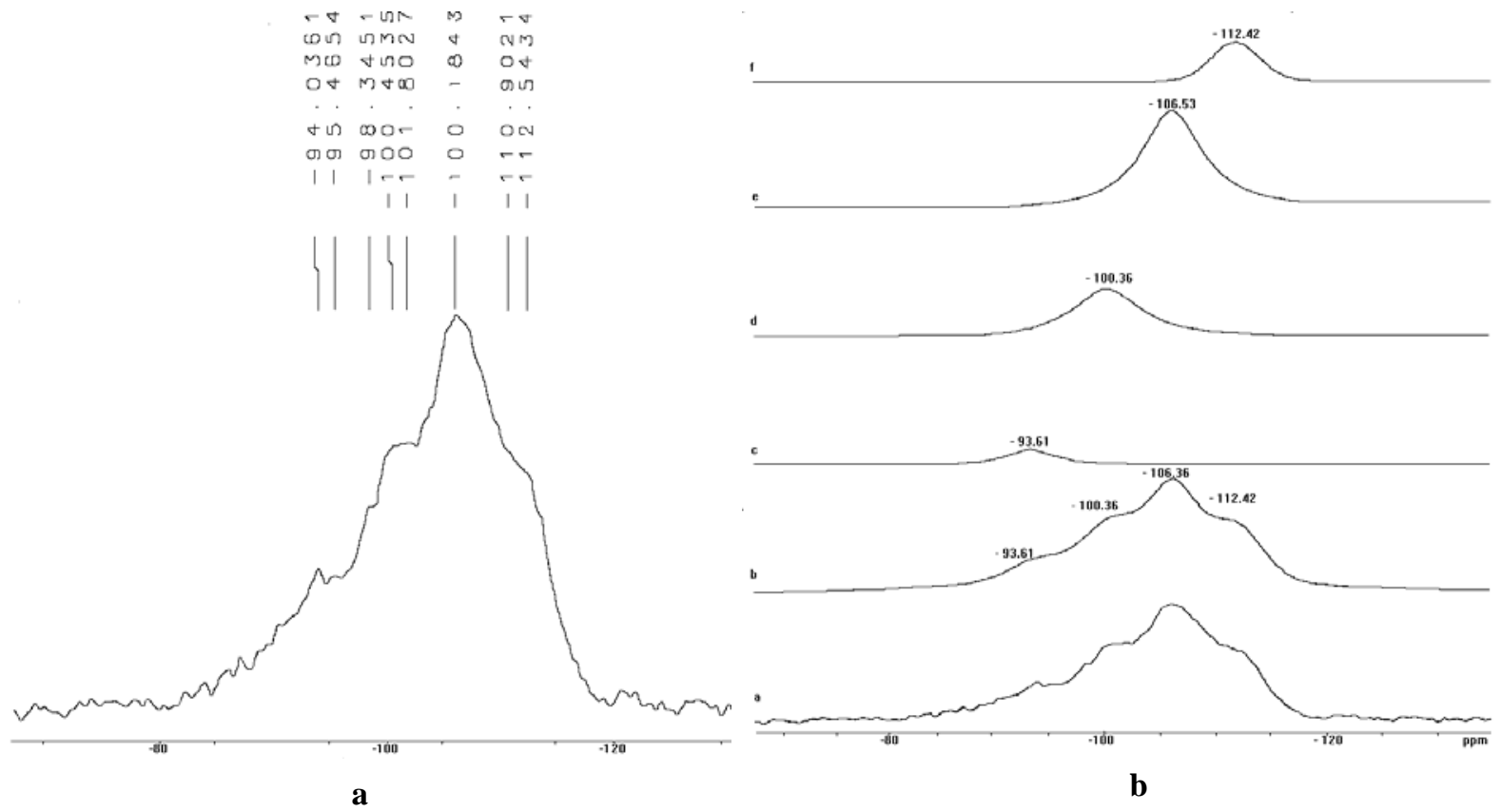

Figure 5. ${ }^{29} \mathrm{Si}$ MAS-NMR spectra of ZBSEO: (a) recorded at $56.62 \mathrm{MHz}$, at a frequency of 8 $\mathrm{KHz}$, and (b) the corresponding deconvoluted spectra.

On the other hand, the ${ }^{27} \mathrm{Al}$ NMR spectrum (Figure 6) showed two resonance signals at 53.30 and $0.47 \mathrm{ppm}$. These chemical shift values lie within the characteristic range for the aluminum tetrahedral and octahedral coordinate framework, $\mathrm{Al}(4 \mathrm{O})$ and $\mathrm{Al}(6 \mathrm{O})$ respectively. The weaker intensity of the octahedral units provide an indication for the presence of not well-hydrated material, ${ }^{19}$ whereas the other equidistant low-intensity signals that appeared in the spectrum are spinning side bands. 


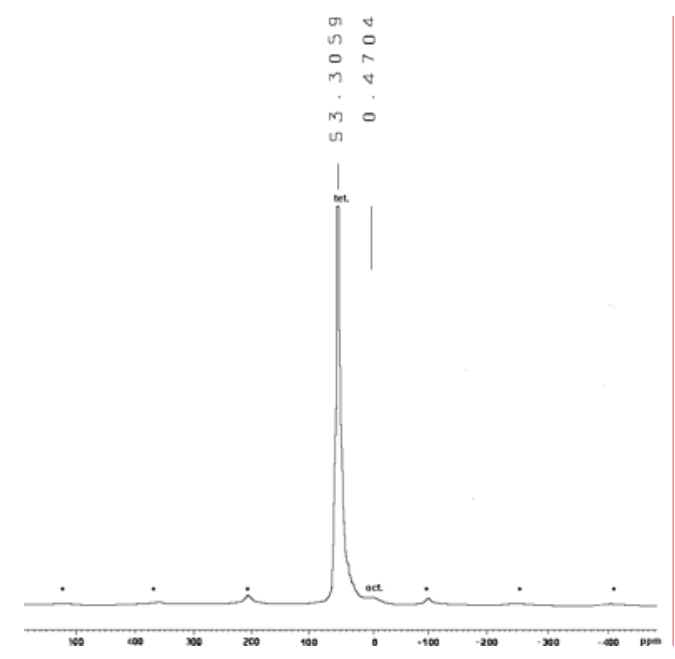

Figure 6. ${ }^{27} \mathrm{Al}$ MAS-NMR of ZBSEO recorded at $78.21 \mathrm{MHz}$, and at spinning frequency of 12 $\mathrm{KHz}$.

The thermograms of the ZBSEO are presented in Figure 7. Loss of water was detected in three different steps, the first one from 27 to $223{ }^{\circ} \mathrm{C}$, where physisorbed water (3.032\%) was eliminated, the second step from 223 to $280{ }^{\circ} \mathrm{C}$, where water trapped in the micropores was eliminated and finally the range from 280 to $760{ }^{\circ} \mathrm{C}$ with a lost of $2.8 \% \mathrm{w} / \mathrm{w}$, of essential water. It is worth mentioning that different endothermic peaks were detected showing the possibility that water molecules were sorbed in different energy position sites, a total lost of $6.326 \% \mathrm{w} / \mathrm{w}$ was detected. Lost of water events were detected by TG/DTG as well as by DTA, under $400{ }^{\circ} \mathrm{C}$, after that temperature $\left(731.25^{\circ} \mathrm{C}\right)$ elimination of structural water is been considered as the probable decomposition of the ZBSEO is carried out. However, the thermal studies indicated that the material is effectively activated at temperatures as low as $100{ }^{\circ} \mathrm{C}$, since the higher acidic activity has been shown by the presence of Brönsted-Lewis acid sites.

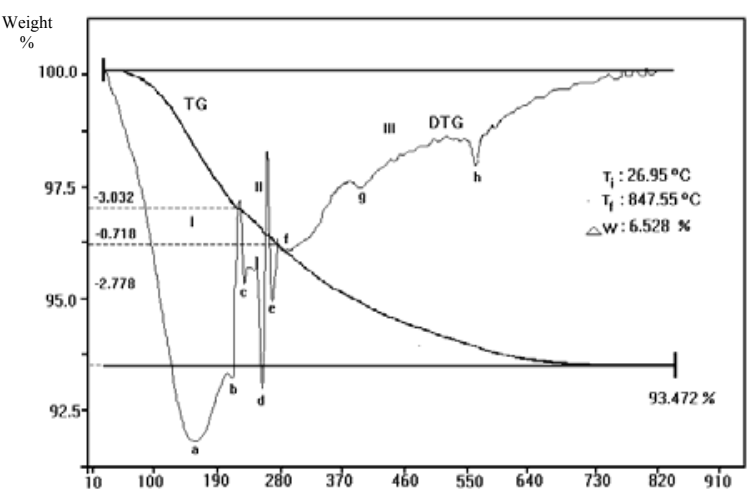

TEMPERATURE ${ }^{\circ} \mathrm{C}$

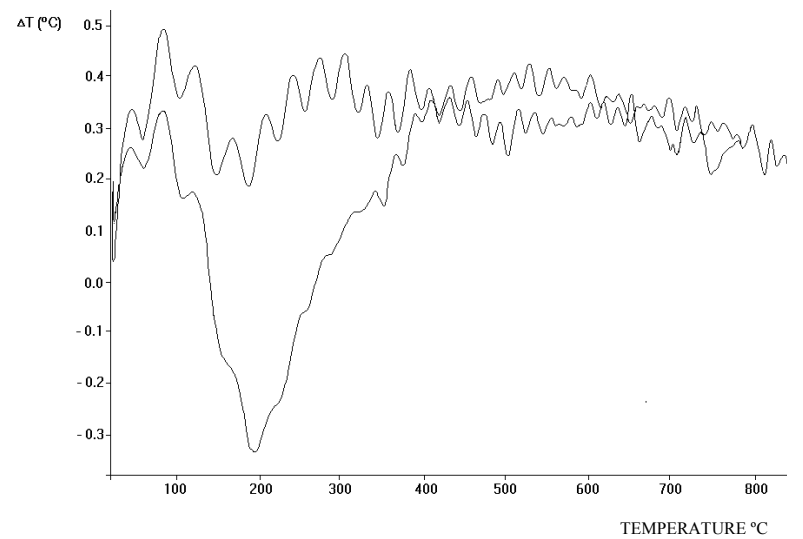

b 
Figure 7. Thermal curves of ZBSEO: Thermograms of DTG-TG (a) and DTA (b). Both heated in air at a dT/dt of $15^{\circ} \mathrm{C} \mathrm{min}{ }^{-1}$ and air flow of $10 \mathrm{ml} \mathrm{min}^{-1}$ with a sample weight of $15 \mathrm{mg}$.

\section{Catalytic activity of the soil}

The reactions catalyzed by the natural material, involved as substrates aldehydic and ketonic moieties and 2-mercaptoethanol as the reagent, producing outstanding yields of the corresponding 1,3-oxathiolane, 1-11 (Table 2). Mostly, the aldehyde compounds employed in this work produced the best transformation percents but, when electrodonating groups or ketones are substituted, the yield decreases substantially due to the higher charge density located on the aldehyde carbonyl group, which implies repulsion electronic effects; complementarily, the lowest yield, the camphorquinone derivative 11, must be due to a steric effect.

Table 2. Oxathiolanes formation

\begin{tabular}{lccc}
\hline \multicolumn{1}{c}{ Substrates } & Oxathiolane & Time $(\min )$ & ${\text { Yield }(\%)^{\mathrm{a}}}^{\mathrm{a}}$ \\
\hline Furfural & $\mathbf{1}$ & 55 & 90 \\
Valeraldehyde & $\mathbf{2}$ & 150 & 90 \\
Benzaldehyde & $\mathbf{3}$ & 65 & 80 \\
Naphtalencarbaldehyde & $\mathbf{4}$ & 90 & 90 \\
p-Anisaldehyde & $\mathbf{5}$ & 50 & 50 \\
Vanillin & $\mathbf{6}$ & 180 & 50 \\
Cyclohexanone & $\mathbf{7}$ & 70 & 50 \\
2-Heptanone & $\mathbf{8}$ & 188 & 70 \\
Acetophenone & $\mathbf{9}$ & 60 & 50 \\
p-Aminoacetophenone & $\mathbf{1 0}$ & 50 & 20 \\
Camphorquinone & $\mathbf{1 1}$ & 435 & 10 \\
\hline
\end{tabular}

${ }^{\mathrm{a}}$ Yields are of isolated pure products.

Once the effectiveness of ZBSEO as catalyst material was tested, it was essential to determine the optimal reaction conditions. To achieve this, the furfural and 2-mercaptoethanol molecules were employed. The results of the dependence of catalyst concentration and reaction time on the promotion of 1,3-oxathiolanes are depicted in Figures 8 and 9, respectively. From these experiments, it was found that the best condition to promote the 1,3-oxathiolane formation include a time of 2 hours and $0.8 \mathrm{~g}$ of ZBSEO material, although the activity is proportional to the ZBSEO amount. Another important outcome, as observed, was that even at the optimum conditions nucleophilic addition can be inhibited by adding a Lewis base (pyridine) to the reaction system. This was shown by admixing several solutions of different concentration of pyridine $(0.274,0.549,0.8241,1.17,1.175,2.31,4.63,6.95$ and $9.26 \mathrm{mmol})$ into the furfuralmercaptoethanol reaction flask Figure 10. It can be observed that the formation percentage of 1,3-oxathiolane decreases substantially when the concentration of pyridine is increased in the 
system. This behaviour can be explained since the introduced Lewis base neutralizes the acid site, consequently reducing the number of active centres. It is worth to notice that $0.0012 \mathrm{mmol}$ of pyridine per gram of ZBSEO material can reduce the 1,3-oxathiolane formation in $65.22 \%$.

Also, the Lewis acidic character of the soil was also demonstrated by the Friedel-Crafts reaction between benzylchloride and toluene; a mixture of ortho and para benzyltoluenes (1:2) with a $90 \%$ of formation, as evidence by GC-MS, was promoted. Finally, the particular identification of each regioisomeric benzyltoluene was established by means of the relative corresponding abundance of the ion $\mathrm{m} / \mathrm{z} 104\left(\mathrm{C}_{8} \mathrm{H}_{6}{ }^{7^{+*}}\right)$, as previously reported in a recently publication. $^{20}$

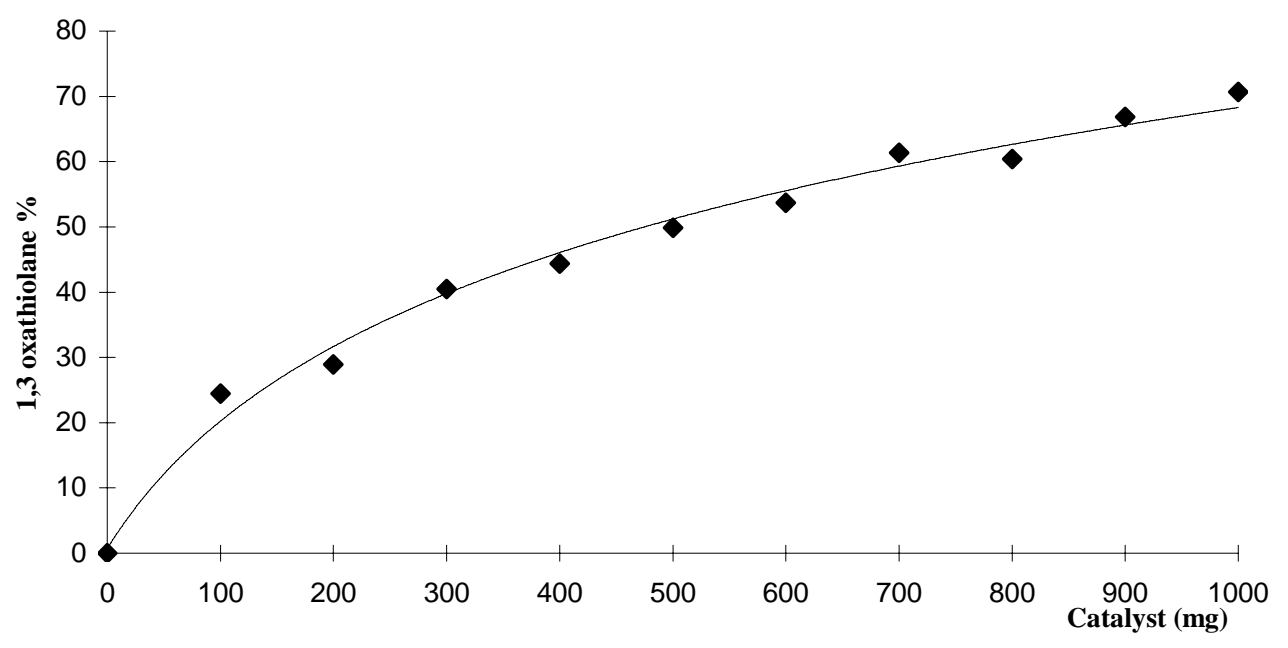

Figure 8. Effect of catalyst concentration on the formation of 1,3 oxathiolanes. Reflux temperature, furfural $5.2 \mathrm{mmol}$ and 2-mercaptoethanol $5.2 \mathrm{mmol}$; reaction time $2 \mathrm{~h}$.

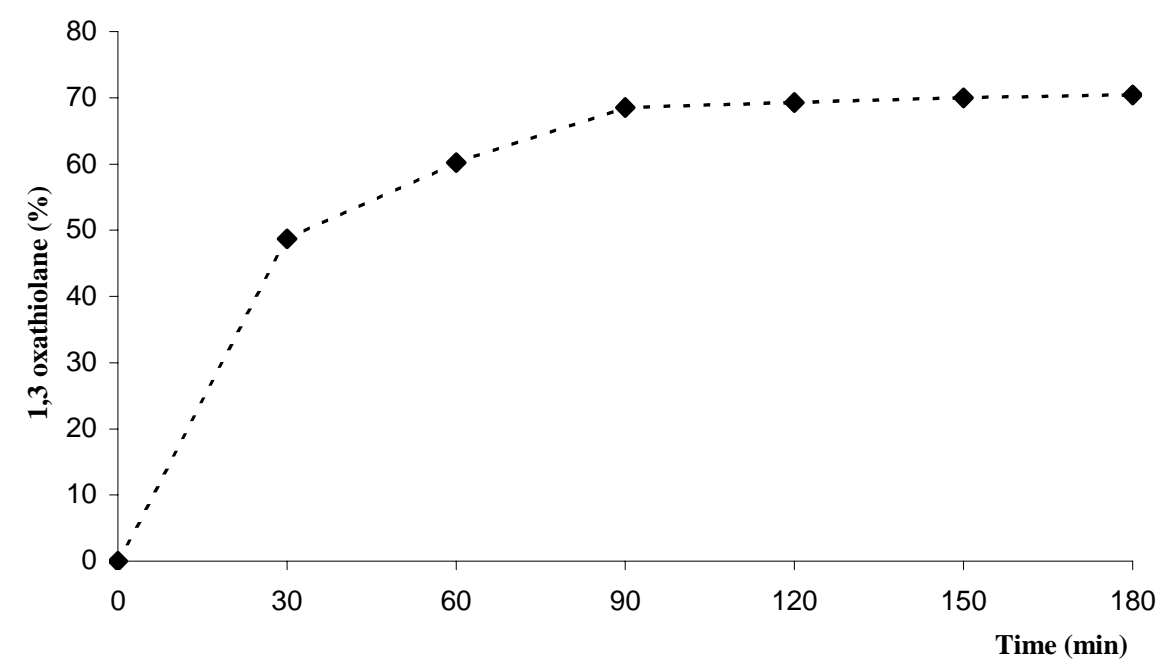


Figure 9. Dependence of the 1,3 oxathiolanes vs reaction time. Reflux temperature, $1 \mathrm{~g}$ catalyst, furfural $5.2 \mathrm{mmol}$ and 2-mercapto ethanol $5.2 \mathrm{mmol}$; reaction time $2 \mathrm{~h}$.

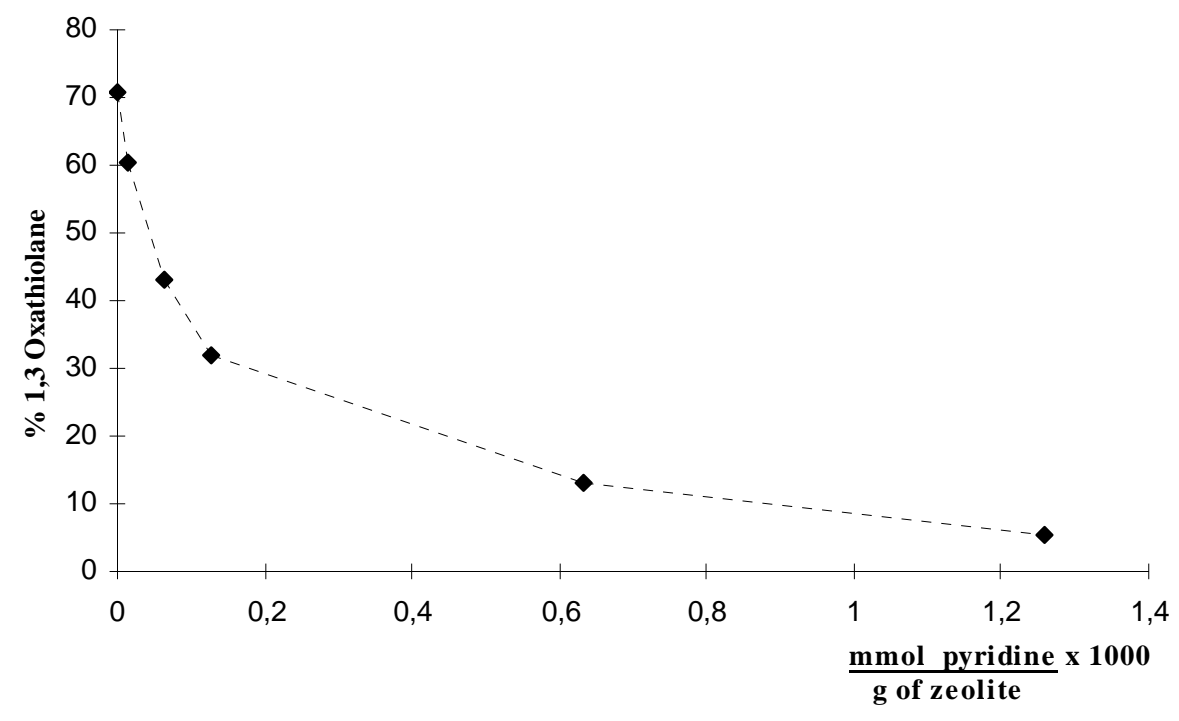

Figure 10. Effect of pyridine concentration on the formation of 1,3-oxathiolane. Reflux temperature, $1 \mathrm{~g}$ catalyst, furfural $5.2 \mathrm{mmol}$ and 2-mercaptoethanol $5.2 \mathrm{mmol}$; reaction time 1.5 h.

\section{Experimental Section}

General Procedures. The carbonyl substrates and the 2-mercaptoethanol (Aldrich), were employed as purchased, benzene and toluene (Aldrich) were dried prior to use ( $\mathrm{Na}^{\circ}$ /benzophenone). The ZBSEO may be directly obtained from a geological formation in Etla, Oaxaca, México and used after drying, at $90{ }^{\circ} \mathrm{C}$, during $72 \mathrm{~h}$. The obtained organic molecules were characterized by spectroscopic methods: ${ }^{1} \mathrm{H}$ NMR spectra were recorded in a Varian FT200 spectrometer using $\mathrm{CDCl}_{3}$ as solvent and TMS as internal reference; EIMS (70ev) spectra were obtained using a JEOL JMS AX 505 HA) mass spectrometer. The conversion percentages for the samples, taken at different times, were determined by gas chromatography coupled to mass spectrometry (GC-MS). Other determinations were carried out by gas chromatography employing a Varian Star 4600 chromatograph equipped with a capillary column $30 \mathrm{~m}$ length by $0.53 \mathrm{~mm}$ diameter, packed with methylphenylsilicon.

ZBSEO Characterization. The BET surface area was measured with ASAP-2000 porosimeter equipment from Micromeritics. Chemical analysis (semi quantitative), size and morphology of particles were determined on a Zeiss DSM 960A scanning electron microscope ( equipped with an X-ray Spectrometer). The chemical analyses were accomplished using a DXA-60 (with a 
detector type SUTW tilted $35^{\circ}$ with respect to sample) energy dispersive X-ray analyzing system, with the SEMIQUANT program, which introduces the ZAF correction. The sample-target directly glued onto a graphite support was introduced in the vacuum $\left(10^{-6} \mathrm{MPa}\right)$ chamber and analyzed under an accelerating voltage of $25 \mathrm{KV}$. Phases identification was carried out in a Xray Siemens D-5000 diffractometer using nickel-filtered $\mathrm{CuK}_{\alpha}(\lambda=1.5406 \AA)$ radiation over $2 \theta$ range of $2^{\circ}$ to $80^{\circ}$ at a scan rate of $2^{\circ} \mathrm{min}^{-1}$. Infrared spectra, using the standard $\mathrm{KBr}$ and probe molecule (pyridine) technique, were carried out on a Nicolet 10-SX Fourier transform infrared spectrum. A wafer of ZBSEO sample was placed into an IR cell and pretreated in vacuum ( $1 \times 10^{-}$ ${ }^{6} \mathrm{mmHg}$ ) at $400{ }^{\circ} \mathrm{C}$ for $1 \mathrm{~h}$. Standard vapor was placed in contact with the activated wafer at room temperature $\left(580 \mathrm{mmHg}, 30 \mathrm{~min}\right.$.) and pumped off in vacuum $\left(1 \times 10^{-6} \mathrm{mmHg}\right)$ for $30 \mathrm{~min}$., and spectra were recorded. The MAS-RMN measurements were carried out, employing a probe of 4 $\mathrm{mm}$, on a Bruker ASX500 spectrometer at $78.21 \mathrm{MHz}\left({ }^{27} \mathrm{Al}\right)$ and $56.62 \mathrm{MHz}\left({ }^{29} \mathrm{Si}\right)$ in an external magnetic field of 7.4 tesla, the silicon spectra were done at spinning frequency of $12 \mathrm{KHz}$ in order to obtain higher resolution. The acquisition and the dwelling time were $36 \times 10^{-3} \mathrm{~s}, 2.9 \mu \mathrm{s}$, $25 \times 10^{-3} \mathrm{~s}, 20 \mu \mathrm{s}$, to aluminum and silicon nuclei respectively. The chemical shifts were measured relative to tetramethylsilane. The thermograms (TGA and DTA) were performed on a Perkin Elmer-7 instrument, in a temperature range of $20-848{ }^{\circ} \mathrm{C}$ (TGA) and $20-1000{ }^{\circ} \mathrm{C}$ (DTA) with approximately $15 \mathrm{mg}$ of sample, the heating rate $\left(\mathrm{dT} / \mathrm{dt}\right.$ ) was $15^{\circ} \mathrm{C} \mathrm{min}{ }^{-1}$ and the air flow 10 $\mathrm{mL} \min ^{-1}$.

Promotion of 1,3 oxathiolanes and benzyltoluenes. 1,3 Oxathiolanes. A mixture of furfural (5.0 mmol), 2-mercaptoethanol (5.2 mmol, $12 \%$ molar in excess), anhydrous benzene (40 mL) and activated soil $(1 \mathrm{~g})$ were placed in a well dried $100 \mathrm{~mL}$ flask equipped with a Dean-Stark tramp. The blend was allowed to reflux under stirring conditions during $2 \mathrm{~h}$. The reaction progress was monitored by tlc ( $n$-hexane/EtOAc 6:4). At the end of the reaction time the mixture was filtered through a celite layer, then washed with acetone; the solvent was removed under vacuum and the product was purified by column chromatography. In general, the obtained, 1,3oxathiolanes (Table 1), were identified by physical and spectroscopical data comparison with authentic samples. ${ }^{21}$

Benzyltoluenes. In an Erlenmeyer glass vessel, anhydrous toluene $(30 \mathrm{~mL})$ was mixed with benzylchloride $(1.2 \mathrm{~g})$, in the presence of ZBSEO $(400 \mathrm{mg})$. The mixture was stirred at refluxing toluene during $3.5 \mathrm{~h}$. The production of the benzyltoluenes was monitored by tlc $\left(\mathrm{SiO}_{2} ; n-\right.$ hexane/EtOAc 9:1; UV, $\mathrm{I}_{2}$ ) as well as by GC-MS until the total disappearance of the reagent $\left(\mathrm{C}_{6} \mathrm{H}_{5} \mathrm{CH}_{2} \mathrm{Cl}\right)$. The resulting mixture was filtered on celite, washed with $\mathrm{NaHCO}_{3}, 5 \%(3 \times 10 \mathrm{~mL})$ and the organic layer was dried with anhydrous $\mathrm{Na}_{2} \mathrm{SO}_{4}$. The remaining toluene was eliminated under reduced pressure and the resulting oil (ortho and para benzyltoluenes 1:1) was characterized by spectroscopic means: ${ }^{1} \mathrm{H}$ NMR $\left(\mathrm{CDCl}_{3} / \mathrm{TMS}, 200 \mathrm{MHz}\right) \delta \mathrm{ppm} 2.20(\mathrm{~s}, 3 \mathrm{H})$, 2.32 (s, 3H), 3.92(s, 2H), 4.00(s, 2H) 7.20m, 9H); $\operatorname{EIMS}(70 \mathrm{eV}) \mathrm{m} / \mathrm{z}(\% \mathrm{ra}): 182(48) \mathrm{M}^{+*} ; 1(100)$ $\mathrm{C}_{7} \mathrm{H}_{7}{ }^{+}$; in addition by comparison with previously reported data. ${ }^{22}$ 


\section{Acknowledgments}

Thanks to DGAPA-UNAM PAPIIT grant IN 208202 for financial support as well as Draucin Jiménez Celis and Pablo Hernández Matamoros for technical assistance.

\section{References and notes}

1. Hoelderich, W.F.; Haft, B. A. Structure-activity and selectivity relationships in heterogeneous catalysis; Elsevier Publishers: Amsterdam, 1991.

2. (a) Adams, J. M. Appl. Clay Sc. 1987, 2, 309. (b) Labial, B.; Villemin, D. Synth. Commun. 1989, 19, 31. (c) Lazlo, P.; May, A. Helv. Chem. Acta 1987, 70, 577. (d) Ghosh, S.; Bauld, N. L. J. Catal. 1985, 95, 300.

3. Meuring, T. Sci. Amer. 1992, 266, 112.

4. Chu, K. C.; Beach, J. W.; Jeong, L.; Choi, B.; Comer, F.; Alves, A. J.; Raymond, R. F. J. Org. Chem. 1991, 56, 6503.

5. Ogawa, K.; Terada, T. Jpn. Kokai Tokkyo Koho JP 1985, 60, 146, 887 [85, 146, 887]. Chem Abs. 1986, 104, 88518z.

6. Franke, W.; Dorfmeister, G.; Ganzer, M.; Johann, G.; Ress, R. Ger. Offen. DE 1989, 3, 821. Chem. Abs. 1990, 112, 235285s.

7. Weissmueller, J.; Kramer, W.; Beng, D. Ger. Offen. D.E. 1985, 3, 324, 769; Chem. Abs. 1985, 103, 54059q.

8. Maslosz, J.; Konopski, L.; Legocki, J. Organika 1991, 17; Chem. Abs. 1992, 116, 194187y.

9. Angeli, P.; Gianella, M.; Pigini, M.; Gualteri, F.; Teodori, E.; Valsecchi, B.; Gaviraghi, G. Eur. J. Med. Chem. Chim. Therm. 1985, 20, 517.

10. Vladimirskaya, E. V.; Novikevich, O. T.; Demchuk, O. G. Farm. Zh. 1991, 6, 67.

11. (a) Berger, N.; Jay, P. IEEE Trans. Elect. Insul. EJ. 21 1986, 59. (b) Lamneck, J. H.; Wise, P. H. Nautl Adris Commun. Aeronaut. Tech. Notes 1950, 17, 2230.

12. Miranda, R.; Arroyo, G. A.; Penierés, G.; Salmón, M.; Cabrera, A.; Alvarez, C.; Delgado, F. Heterocyclic Preparative Chemistry 1980-2003, Research Trends 2003 in Press. Miranda, R.; Rios, H.; Delgado, F.; Castro, M.; Cogordan, A.; Salmón, M. Appl. Catal. A General 2003, 244, 217.

13. Cseri, T.; BéKássy, S.; Figueras, F.; Eceke, E.; Menorual, L. C.; Dutartre, R. Appl. Catal. A: General 1995, 132, 141.

14. Paunkshysis, E. A.; Yurchenko, E. N. Russ. Chem. Rev. 1983, 3. Barzetti, T.; Selli, E.; Mosotti, D.; Forni, L. J. Chem. Soc. Faraday Trans. 1996, 22, 1401.

15. Kinsey, R. A.; Kirkpatrick, R. J.; Hower, J.; Smith, K. A.; Oidfield, E. Am. Mineral 1985, 537.

16. Limppa, E.; Mâgi, M.; Samosono, A.; Tramas, M.; Engelhardt, G. J. Am. Chem. Soc. 1981, 103, 4992. 
17. (a) Limppa, E.; Mâgi, M.; Samosono, A.; J. Am. Chem. Soc. 1986, 108, 1730. (b) Hay, G. R.; Van Erp, W. V.; Alma, N. C. M.; Couperus, P. A.; Huis, R.; Wilson, A. E. Zeolite 1984, 4, 377 .

18. Limppa, E.; Mâgi, M. J. Phys. Chem. 1984, 88, 1518.

19. Memhold, R. H.; Tapp, N. J. J. Chem. Soc. Chem. Commun. 1990, 219.

20. Miranda, R.; Delgado, F.; Velasco, L.; Pérez, J.; Salmón, M. Rapid Commun. Mass Spectrom. 2000, 14, 188.

21. (a) Maslosz, J.; Konopski, L.; Legocki, J. Organika 1991, 17; Chem. Abs. 1992, 116, 194187y. (b) Kazuyuki, Y. Chem. Abs. 1992, 116, 255600b. (c) Romo, J.; Rosenkranz, G.; Djerassi, Y. C. J. Am. Chem. Soc. 1951, 73, 4961. (d) Mizuno, T.; Nakamura, F.; Ishino, Y.; Nishiguchi, I.; Hirashima, T. Synthesis 1989, 770; Chem. Abs. 1990, 112, 178740k. (e) Mustafa, J.; Saed, M. T.; Osman, S. M. J. Am. Oil. Chem. Soc. 1991, 68, 313; Chem. Abs. 1991, 115, 49180r. (f) Taguchi, Y.; Yanagiya, K.; Shibuya, Y.; Suhara, Y. Jpn. Kokai Tokkyo Koho JP, 1988, 63, 218, 672, [88, 218, 672]; Chem. Abs. 1989, 110, 212827q. (g) Elkinson, R. S.; Eremeev, A. V.; Liepins, E. Khim. Geterotsikl. Soedin. 1984, 1575; Chem. Abs. 1985, 102, 78792d. (h) Seebach, D.; Naef, R.; Calderari, G. Tetrahedron 1984, 40, 1313.

22. (a) Hartman, W.; Ross, P. Org. Synth. 1943, 14, 34; Chem. Abstr. 1939, 33, 7745; Chem. Abstr. 1955, 49, 12391d. (b) Vingiello, F. A.; Sih-Gwan, Q.; Sheridan, J. J. Org. Chem. 1961, 26, 3202. (c) Ando Kawate, T.; Ichihara, T.; Hanafusa, J. Chemistry Lett. 1984, 725; Chem. Abstr. 1972, 77, 101092b; Chem. Abstr. 1976, 84, 105173w. 